\title{
The functional biology of Strombidium sulcatum, a marine oligotrich ciliate (Ciliophora, Oligotrichina)
}

\author{
Tom Fenchel ${ }^{1}$, Per R. Jonsson ${ }^{2}$ \\ ${ }^{2}$ Marine Biological Laboratory (University of Copenhagen), Strandpromenaden 5, DK-3000 Helsingør, Denmark \\ ${ }^{2}$ Tjärnö Marine Biological Laboratory, Pl. 2781, S-452 00 Strömstad, Sweden
}

\begin{abstract}
The bioenergetics and swimming behaviour of the marine oligotrich ciliate Strombidium sulcatum were studied. It grows on bacteria and heterotrophic flagellates with a maximum rate around $0.1 \mathrm{~h}^{-1}$. Cell yield is $3.3 \times 10^{-5}$ ciliates bacterium ${ }^{-1}$ and $7.7 \times 10^{-3}$ ciliates flagellate $^{-1}$ indicating a gross growth efficiency around 0.5 . Starvation of $S$. sulcatum is accompanied by a 10 -fold reduction in cell volume with a mean survival time of about $70 \mathrm{~h}$. Clearance decreases rapidly for particles smaller than about $2 \mu \mathrm{m}$ and cannot be detected for $0.21 \mu \mathrm{m}$ beads. Maximum clearing rate for $2.83 \mu \mathrm{m}$ latex beads is $1.6 \mu \mathrm{h} \mathrm{h}$, close to the clearing rates found for bacteria, $\left(1.5 \mu \mathrm{lh} \mathrm{h}^{-1}\right)$ and flagellates $\left(2 \mu \mathrm{h} \mathrm{h}^{-1}\right)$ and also to the calculated volume of water filtered $\left(2.5 \mu \mathrm{h} \mathrm{h}^{-1}\right)$. S. sulcatum efficiently accumulates in patches of bacteria. Analysis of ciliate behaviour revealed that this is caused by changes of swimming pattern from a helical path to a closed circle in response to bacterial density and that this response is chemically induced. This modulation of swimming behaviour when encountering a bacterial patch results in a 20 fold decrease in transportation rate with only a $40 \%$ reduction in swimming speed. Video recordings of swimming ciliates in strobe-light suggest that the membranelles can change their position to affect the axial rotation of the ciliate. Absence of axial rotation results in a circular swimming path. In addition to this kinetic response, a transient response was observed which further enhances the probability of finding and remaining in bacterial patches. It was also found that $S$. sulcatum changes its vertical distribution in response to nutritional status; this is at least in part due to the kinetic response, but change in cell morphology may also play a role. Findings are interpreted as adaptations for exploiting heterogeneous environments. The scale of the patchiness which the ciliate can exploit is about $1 \mathrm{~m}$.
\end{abstract}

\section{INTRODUCTION}

Several studies recognize the significance of protozoa in aquatic ecosystems (e.g. Fenchel 1987) and there is a growing interest in their functional properties in relation to their ecological role. Recent work has studied e.g. bioenergetics and food selection in some groups, but other aspects are poorly understood. An important aspect of protozoan life on which information is scarce and speculations abound concerns the ecological significance and mechanisms of behaviour.

Protozoa possess simple sensory organelles and a low capacity for information processing and so are likely to have a limited repertoire of behaviours. Nevertheless, physiological studies show that protozoa can respond to light (Song et al. 1980, Reisser \& Häder 1984), a wide range of chemicals (Van Houten et al. 1975, 1981, Levandowsky \& Hauser 1978), mechanical stimuli
(Naitoh \& Eckert 1974) and even gravity (Fenchel \& Finlay 1984,1986 a). However, little is known about the ecological consequences of these sensory capabilities and only a few studies on these exist (Fenchel \& Finlay 1984, Finlay \& Fenchel 1986, Finlay et al. 1987). Given the constraints of protist behaviour it is interesting to learn how they orient themselves in heterogeneous environments and with what efficiency they exploit patchily distributed resources. Fenchel \& Finlay (1984, 1986b) and Finlay et al. (1987) have shown how seemingly complex distributions of limnic ciliates can be explained by combinations of a few simple types of behaviour. This indicates that simple mechanisms may also be used by protozoa to exploit patchy food resources. In this paper we describe the functional biology of a marine oligotrich ciliate including an experimental analysis of behaviour in prey gradients and its ecological implications. 


\section{MATERIALS AND METHODS}

Materials. Strombidium sulcatum Claparède \& Lachmann was isolated both from the Mediterranean Sea (Rivier et al. 1985) and from Limfjorden, Denmark, and subsequently cultured on mixed bacteria supplied with wheat grains. For observations of $S$ sulcatum with scanning electron microscopy, cells were fixed in a mixture of $\mathrm{OsO}_{4}\left(2 \%\right.$ w/v) and $\mathrm{HgCl}_{2}$ (sol. sat.), (6:1), filtered onto 1 um nuclepore filters, dehydrated in a critical point dryer, covered with gold and examined with a Jeol scanning electron microscope. An ultrastructural description of $S$. sulcatum can be found in Fauré-Fremiet \& Ganier (1970). Cultures of the oligotrich ciliates $S$. reticulatum (Leegaard) and $S$. vestitum (Leegaard), originally isolated from Kosterfjorden (Sweden), were fed a prasinophycean algae, Pyramimonas sp. In all experiments with bacteria a Pseudomonas sp. grown on seawater agar medium (Zobell 1941) was used.

Growth experiments. In separate batch cultures the growth rate of Strombidium sulcatum was measured as a function of concentration of bacteria Pseudomonas sp., and of a heterotrophic flagellate, Pteridomonas danica. Cultures with bacteria were prepared by scraping colonies from agar plates and suspending them in filtered and autoclaved seawater (Fenchel 1982). The flagellate was grown on Pseudomonas sp. in batch cultures and used when most bacteria had been ingested. All experiments were carried out at room temperature $\left(20^{\circ} \mathrm{C}\right)$. Changes in number of ciliates and prey in the growth experiments were followed by sampling at regular time invervals. Ciliates and heterotrophic flagellates were fixed in Lugols solution and counted in a counting chamber. Bacteria were quantified spectrophotometrically at $660 \mathrm{~nm}$ and converted to cell number using standards of known concentrations. Growth rate was calculated from the initial phase of exponential growth. Cell yield in growth experiments was determined as the concentration of ciliates at the moment when cell volume starts to decrease divided by the initial concentration of prey

To examine effects of starvation, survival and cell volume of Strombidium sulcatum was studied following the reduction of food in the growth experiments. Cell volume was calculated from linear dimensions (of Lugol-fixed cells) assuming a geometric shape described by 2 ellipsoids.

Particle selection. Particle selection and ingestion rates of Strombidium sulcatum were determined in particle uptake experiments. Exponentially growing ciliates were incubated together with a series of 4 concentrations of suspended latex beads of the following kinds: $0.21 \mu \mathrm{m}$ fluorescent, $0.51 \mathrm{\mu m}$ fluorescent,
$0.8 \mu \mathrm{m}$ blue, $1.1 \mu \mathrm{m}$ fluorescent and $2.83 \mu \mathrm{m}$ non-dyed (Biosphere, Polyscience, USA). Four different concentrations for each particle size were used. After 5 min the experiments were stopped with glutaraldehyde $(2.5 \%)$ and the ciliates (10 to 30 cells) examined microscopically to count individual, ingested beads $(\mathrm{SE}<10 \%)$, and the volume cleared of particles was calculated. Experimental details, precautions and limitations of this technique are discussed in Fenchel (1986).

Clearing rates of bacteria and heterotrophic flagellates were also calculated from growth experiments. Clearing rate for ciliates growing on bacteria was calculated as: $F_{\max }=\mu_{\max } /(\mathrm{K} \cdot \mathrm{Y})$, where $F_{\max }$ is maximum clearing rate, $\mu_{\max }$ is maximum growth rate, $\mathrm{K}$ is the halfsaturation constant and $\mathrm{Y}$ is yield (Fenchel 1982). In the experiments where Strombidium sulcatum was grown on heterotrophic flagellates clearing rate was also calculated from the rate of disappearance of flagellates.

Attraction of ciliates to patches of prey. Colonies of bacteria were suspended in sterile seawater and immobilized with heat $\left(80^{\circ} \mathrm{C}\right)$. A drop of bacterial suspension stained with methylblue was injected into a Sedgewick-Rafter counting chamber already filled with $1 \mathrm{ml}$ of a suspension of Strombidium sulcatum. The accumulation of ciliates in the patch of bacteria as a function of time was then followed with a dissecting microscope. The diffusion of the bacterial patch (and of any leaking substances) could be monitored by the blue stain and covered 2 to $5 \%$ of the total chamber area. Similar experiments were also performed with 2 other Strombidium species, S. reticulatum and S. vestitum. The accumulation rate of $S$. sulcatum was also studied (by video-recording, see below) as a function of mean distance from the patch. This was done by varying the volume of ciliate culture in the counting chamber.

Test of a chemical cue. We examined whether the attraction of Strombidium sulcatum in the presence of bacteria was caused by chemosensory responses. Three capillary tubes were filled with a suspension of living bacteria, a peptone solution and filtered and autoclaved seawater, respectively. The tubes were sealed with petrol jelly in one end and with a cotton plug in the other. The cotton plug was firmly packed to retain the bacteria inside the tube while allowing dissolved substances to leak out. The tubes were placed in a culture dish with filtered and autoclaved seawater and 50 washed $S$. sulcatum were added. After about $4 \mathrm{~h}$ the accumulation of ciliates around the capillary tubes was noted.

Analysis of swimming pattern. Swimming ciliates placed in a Sedgewick-Rafter chamber were either photographed in dark field ( 1 s exposure) or recorded 
with a video recorder (Sony video camera DXC-101P and Panasonic recorder AG-6200) fitted to a dissecting microscope. Video-recorded movements of individual ciliates were analyzed by plotting ciliates frame by frame on a plastic film covering the monitor screen allowing a time resolution of $1 / 25 \mathrm{~s}$. Swimming behaviour as a function of prey density was studied either around a patch of bacteria (prepared as described above) or in a series of culture dishes with different concentrations $\left(10^{4}\right.$ to $\left.10^{8} \mathrm{ml}^{-1}\right)$ of homogeneously suspended, living bacteria. To reduce bacteria coming from the stock cultures, ciliates were washed several times in filtered and autoclaved seawater before the experiments.

The behavioural response of Strombidium sulcatum swimming in a chemical gradient without prey was studied in the vicinity of small agar blocks with peptone or bacterial extracts. An agar cube of about $0.5 \mathrm{~mm}^{3}$ was cut out and placed in a Sedgewick-Rafter counting chamber. Ciliates were then added and swimming paths were reconstructed as described above.

Study of membranelle function. Strombidium sulcatum swimming in circles or in helices were video recorded through a microscope (200 to $1000 \times$ ) using strobe-light as light source. The strobe flashes were sufficiently short to freeze the beating membranelles. The short strobe flash $(<1 / 100 \mathrm{~s})$ exposes the video pickup device to the image for a brief fraction of the field time and the pattern of resulting electrical charge is stored until it is swept at the standard scan rate. The use of a solid-state pickup device (CCD) ensured minimal lag, burn and geometric distortion (for more details see Inoué 1986). Sequences were played frame by frame and membranelles traced from the screen on plastic films.

Vertical distribution. The vertical distribution of Strombidium sulcatum as a function of starvation was studied in wide $100 \mathrm{ml}$ test tubes. Tubes were placed in a stirred water bath to reduce heat convection and filled with a dense culture of growing ciliates and placed in the dark. The vertical distribution of the population was monitored over 1 wk taking $0.2 \mathrm{ml}$ samples at 4 depths from surface to bottom. In a separate experiment the change of vertical distribution upon feeding of starved ciliates was studied in a spectrophotometer cell.

To test if the ability of Strombidium sulcatum to actively swim downwards is caused by true geotaxis, implying physiological perception of gravity, an experiment was designed where swimming direction was studied as a function of density of the medium. The hypothesis was that raising the medium density and thus reducing the sinking rate of the ciliates should not dramatically alter geotaxic behaviour if a gravity-sensing organelle exists, but this would be the case if an apparent geotaxis is the result of hydrodynamical reorientation due to gravitational sinking and an asymmetric cell shape. Density of the medium was increased with heavy water (deuteriumoxide, $p=$ $1.11 \mathrm{~g} \mathrm{~cm}^{-3}$ ) and the swimming angle to the vertical of S. sulcatum was determined from photographs taken through a horizontally set dissecting microscope with 1 s exposure time. The long exposure time outlined the ciliates as white paths on the photographs, but since it was not possible to distinguish the polarity of the paths only absolute values of angles $\left(0\right.$ to $\left.90^{\circ}\right)$ to the vertical could be measured. To further test the hypothesis that the non-random vertical distributions were caused by hydrodynamical reorientation of cells, ciliates were treated with $\mathrm{NiNO}_{3}(1 \mathrm{mM})$ which blocks ciliary reversals and so random reorientation.

\section{RESULTS AND DISCUSSION}

\section{Natural habitats and morphology}

Strombidium sulcatum has previously been reported from marine sediments rich in organic material (FauréFremiet 1924, Kahl 1932, Fauré-Fremiet \& Ganier 1970), from algal mats in a tidal marsh (Borror 1965) and isolated from plankton (Rivier et al. 1985). In the present study we have observed $S$. sulcatum on the surface of organically rich sediments and on Beggiatoa mats. The observed habitats of $S$. sulcatum together with the behaviour described below indicate that it is primarily a benthic form which occasionally occurs in the plankton. Because it grows fast on bacteria and heterotrophic flagellates even a single individual in a large pelagic water sample is likely to grow into a dense population upon enrichment or if the sample is left to stand.

The general morphology of Strombidium sulcatum is similar to most other Strombidium species with an open adoral zone of membranelles $(14+7$ oral membranelles) consisting of closely set cilia, a conical shape and the cap of cortical plates covering the posterior end (Fig. 1). It may be distinguished from most other species of Strombidium by the relatively small cap of cortical plates and its dimensions (length: 30 to $35 \mu \mathrm{m}$, greatest diameter: 20 to $25 \mu \mathrm{m}$ ); moreover it is not flattened as many other benthic species. In contrast to many planktonic species which are green due to incorporated plastids (Laval-Peuto \& Febvre 1986, Jonsson 1987. Stoecker et al. 1987), S. sulcatum is colourless. However, there is at least one planktonic species which is similar in appearance to S. sulcatum; it conforms to the $S$. emergens described by Leergaard (1915), but this species does not show the changes in swimming pattern as described below. 

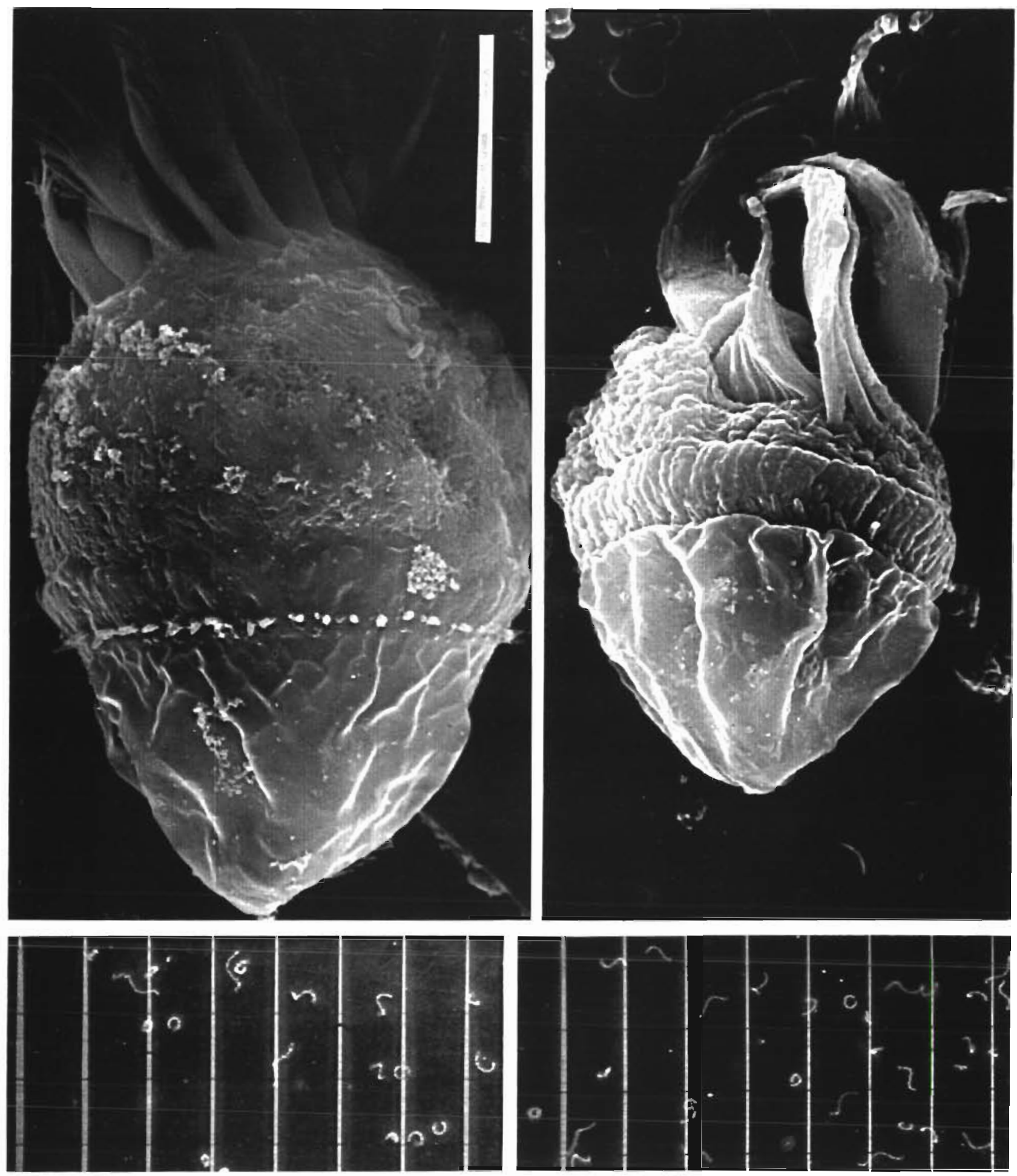

Fig 1. Strombidium sulcatum. Above: SEM micrographs; left: growing cell, right: starving cell; Scale bar $=10 \mu \mathrm{m}$. Below: $1 \mathrm{~s}$ exposure photographs showing swimming paths; left: growing cells, right: moderately starving cells. White lines are spaced $1 \mathrm{~mm}$ apart 


\section{Bioenergetics}

When a small number of Strombidium sulcatum are inoculated together with Pseudomonas $\mathrm{sp}$. or Pteridomonas danica, ciliates start to divide and increase exponentially in numbers (Fig. 2). The numerical response (Fig. 3) could be fitted to a hyperbolic function which has been found for other growing ciliates and heterotrophic flagellates (Heinbokel 1978, Fenchel 1982, Jonsson 1986). Maximum growth rate is about $0.12 \mathrm{~h}^{-1}\left(\mathrm{~T}_{2}=5.8 \mathrm{~h}\right)$. Cell yield is $3.3 \times 10^{-5}$ ciliates bacterium ${ }^{-1}$ and $7.7 \times 10^{-3}$ ciliates flagellate ${ }^{-1}$ and nearly invariant with growth rate (Fig. 4). The volume of the ciliate is about $9000 \mathrm{\mu m}^{3}$ when growing on bacteria (volume: $0.6 \mu \mathrm{m}^{3}$ ) and about $6500 \mu \mathrm{m}^{3}$ when growing on flagellates (volume: $80 \mu \mathrm{m}^{3}$ ); in both cases yield expressed as volume ciliates per volume ingested food is around $50 \%$ assuming that fixation did not appreciably change cell volume.

When food supply is exhausted, Strombidium sul- catum responds with 1 or 2 final divisions without any intermediate cell growth resulting in a concomitant reduction of cell volume (Fig. 2). During the following period there is a further gradual decrease in cell volume. In our experiments the response to the reduction of food was sudden and dramatic for ciliates growing on bacteria but less marked and gradual for ciliates growing on flagellates; we do not know the reason for this. Survival is high during the first $50 \mathrm{~h}$ of starvation; thereafter mortality increases and after $85 \mathrm{~h}$ only $10 \%$ of the population remains.

The size spectrum of ingested particles is shown in Fig. 5. Clearance shows a marked decrease for $1.1 \mu \mathrm{m}$ latex beads relative to $2.8 \mu \mathrm{m}$ beads and $0.51 \mu \mathrm{m}$ beads are cleared at only $5 \%$ of the rate shown for $2.83 \mu \mathrm{m}$ beads. No ingestion of $0.21 \mu \mathrm{m}$ beads could be detected. The reduction of clearing rate below $2 \mu \mathrm{m}$ is consistent with the distances between membranelles (Fig. 1) which are supposed to act as a filter (Fenchel 1986, Jonsson 1986). Strombidium species have about 7
Fig 2. Strombidium sulcatum. (a) Batch culture initiated with $5 \times 10^{6}$ bacteria $\mathrm{ml}^{-1}$ showing ciliate number and volume. (b) Batch culture initiated with $4 \times 10^{4}$ heterotrophic flagellates $\mathrm{ml}^{-1}$ showing the number of ciliates and flagellates together with ciliate volume

Fig. 3. Strombidium sulcatum. Growth rate as function of food concentration, (a) on bacteria, (b) on flagellates
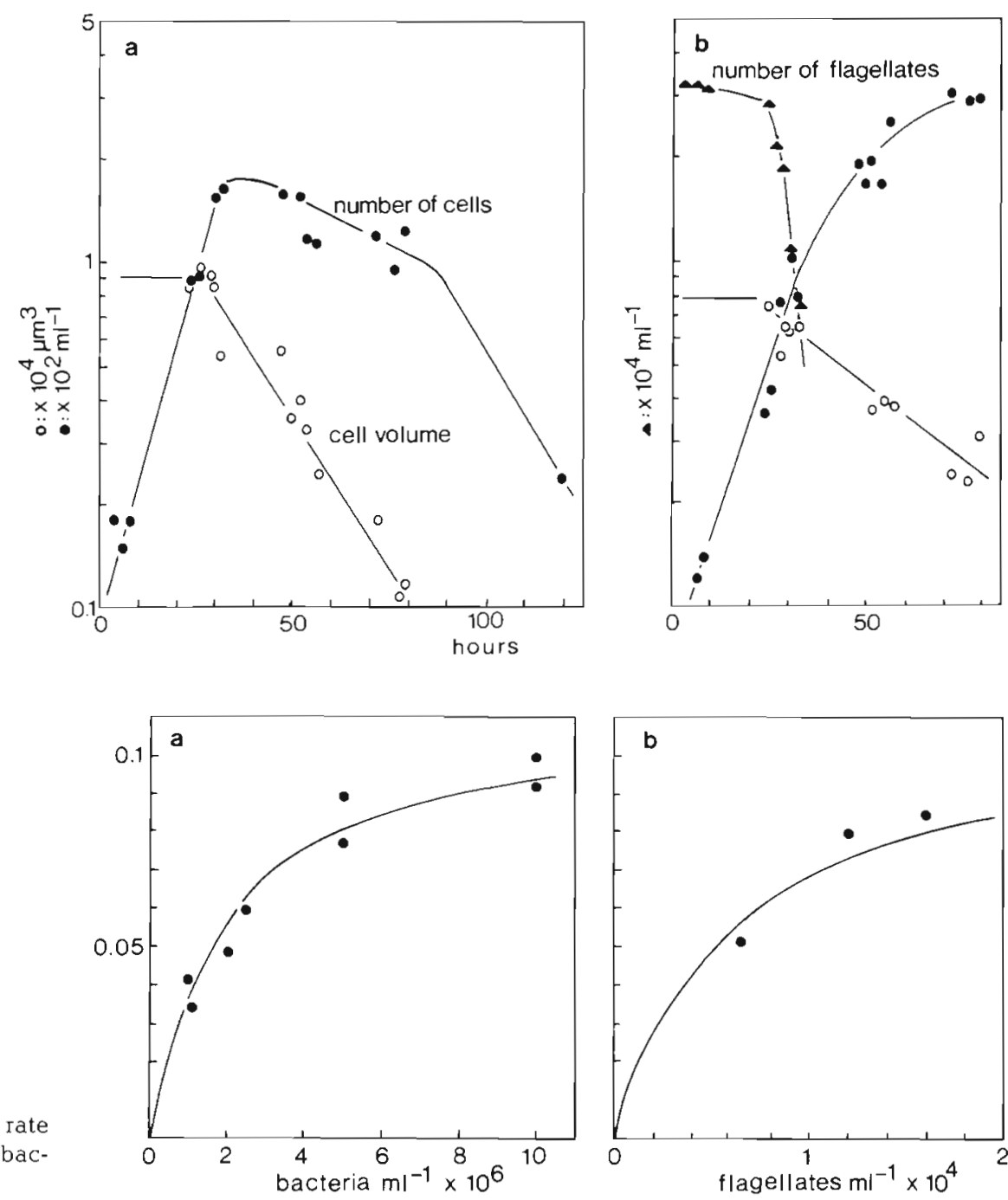


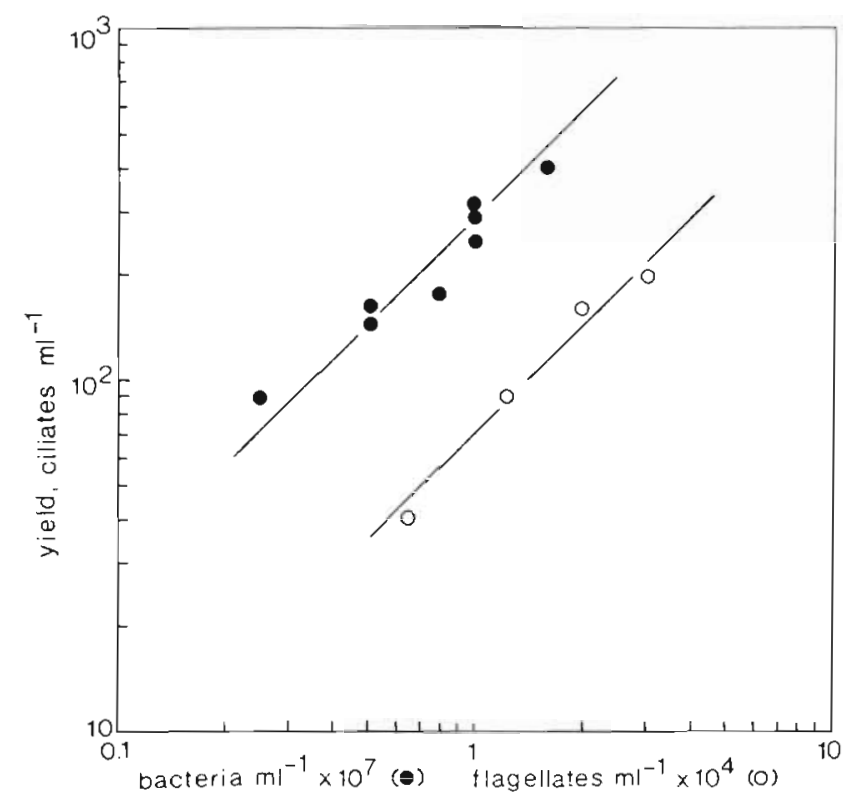

Fig. 4. Strombidium sulcatum. Cell yield as function of initial food concentrations

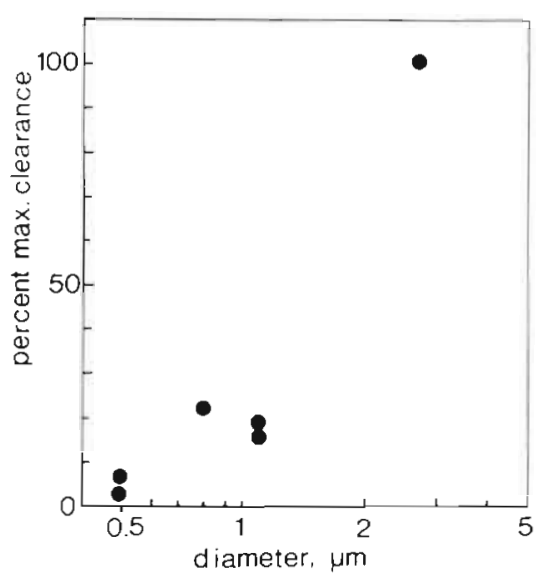

Fig. 5. Strombidium sulcatum. Maximum clearing rate as function of particle size. Clearance for $2.83 \mu \mathrm{m}$ particles is set to $100 \%$

small oral membranelles which are more closely set (distance about $0.5 \mu \mathrm{m}$ ) than the larger membranelles. It may be speculated that the plateau between 1.1 and $0.8 \mu \mathrm{m}$ beads is caused by retention of these particles by the small oral membranelles which become leaky to particles around $0.5 \mu \mathrm{m}$ as indicated in Fig. 5. Thus the filtering system may be considered as consisting of 2 filters with different mesh sizes and flow rates. In absolute terms maximum clearing rate of $2.83 \mu \mathrm{m}$ beads was $1.6 \mu \mathrm{h} \mathrm{h}^{-1}$ which was close to the calculated clearance of bacteria and flagellates of about 1.7 and $2.2 \mu \mathrm{l}$ $\mathrm{h}^{-1}$ respectively. These estimates agree with a calculated filtering rate of about $2.5 \mu \mathrm{h} \mathrm{h}^{-1}$ assuming a swim- ming velocity of $600 \mu \mathrm{m} \mathrm{s}^{-1}$ when feeding and a crosssectional area including the membranelles of $1200 \mathrm{\mu m}^{2}$. Volume-specific clearance is about $2 \times 10^{5}$ volumes $h^{-1}$ which is consistent with most studied polyphymenophoran ciliates (Fenchel 1986). The maximum growth rates of $S$. sulcatum are similar to other small ciliates feeding on bacteria (Fenchel \& Finlay 1983). Rivier et al. (1985) presented estimates of growth rates of S. sulcatum growing on mixtures of marine bacteria. Results vary considerably between treatments $(0.03$ to $0.14 \mathrm{~h}^{-1}$ ), maybe because of varying composition of bacteria. Maximum growth rate of the planktonic $S$. reticulatum growing on micro-algae was reported to be more modest, $0.036 \mathrm{~h}^{-1}$, (Jonsson 1986) but since the experiments were carried out at $12^{\circ} \mathrm{C}$ growth rates might be doubled at $20^{\circ} \mathrm{C}$. Still, the estimate seems somewhat lower than for $S$. sulcatum perhaps reflecting differences in food quality. The gross growth efficiency for $S$. sulcatum expressed as cell yield in terms of volume was consistent with the estimates between 40 to $60 \%$ which have been found for several other protozoa (Fenchel \& Finlay 1983). Particle size selection of $S$. sulcatum is comparable to the planktonic species S. reticulatum and $S$. vestitum (Jonsson 1986) which showed a similar drop in clearing rate for particles smaller than $2 \mu \mathrm{m}$. This characteristic is shared by many polyhymenophoran ciliates that retain particles between the membranelles (Fenchel 1986).

The low clearing rates for particles smaller than $1 \mu \mathrm{m}$ indicate that high food concentrations are necessary if Strombidium sulcatum is to grow on planktonic bacteria. Assuming that the ability to modulate growth rate in relation to available food is an adaptation to changing food conditions, the growth half-saturation constant may be used as a rough measure of the average food concentration experienced by the organisms. Half-saturation concentration with Pseudomonas sp. as food is $2.5 \times 10^{6}$ cells $\mathrm{ml}^{-1}$ and with flagellates it is $6.5 \times 10^{3}$ cells $\mathrm{ml}^{-1}$. The concentration of flagellates corresponds well to average total nanoplankton of marine plankton at least in coastal areas (Andersen \& Sørensen 1986). This also applies to the concentration of bacteria but the Pseudomonas sp. used in our experiments is a large rod-shaped bacterium measuring $1.5 \times 0.8 \mu \mathrm{m}$ while bacteria in the marine pelagial are generally smaller and often spherical. McManus \& Fuhrman (1986) measured the size of marine planktonic bacteria and estimated an average diameter of $0.5 \mu \mathrm{m}$. This smaller bacterial size will result in lower clearing rate (conservatively by a factor of 5) and less food for each captured particle by $S$. sulcatum. To obtain the half-saturated growth rate the concentration of natural bacteria would have to be around $7 \times 10^{7} \mathrm{ml}^{-1}$, concentrations normally found only in sediments, along surfaces or locally around decaying organic matter. 
Fig. 6. Strombidium sulcatum. Accumulation in a patch of bacteria. The curve in (a) is based on the regression line of the same data as presented in (b). Areas inand outside the patch were 30 and 970 $\mathrm{mm}^{2}$, respectively. Results can be explained as chemokinesis if the motility of the ciliates is about 50 times higher outside than inside the patch
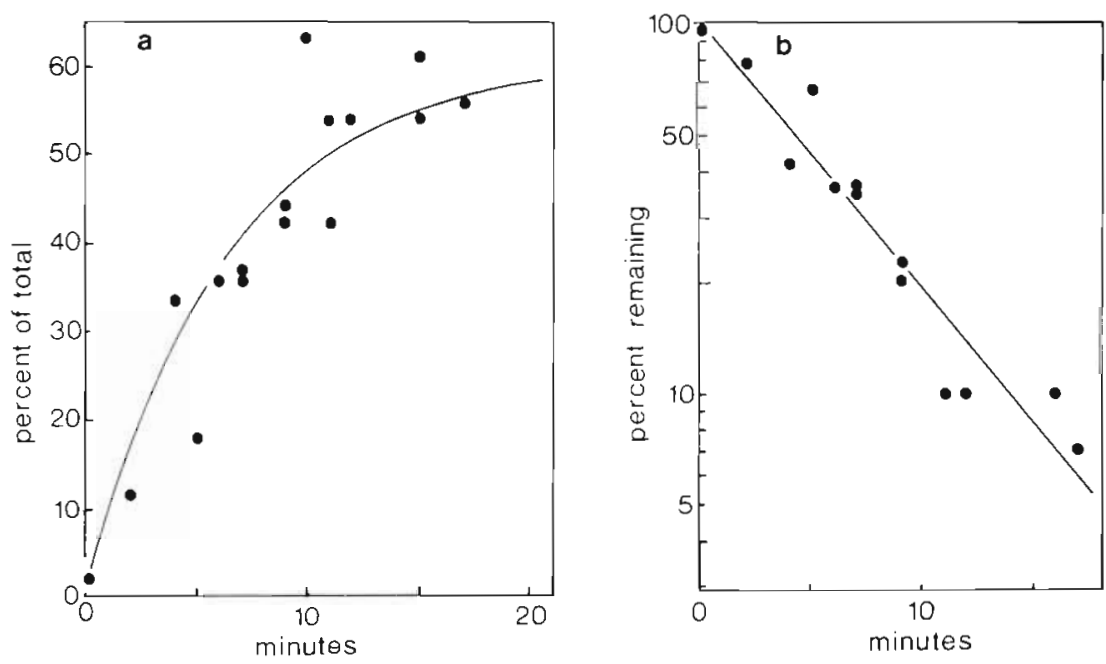

\section{Behaviour}

When Strombidium sulcatum cells swim in a flat chamber with a small patch of concentrated living or heat-killed bacteria, ciliates immediately accumulate (Fig. 6). In the filled chamber $(2 \times 5 \mathrm{~cm})$ an equilibrium distribution is reached with ca $60 \%$ of the ciliates swimming in the bacterial patch (ca $0.3 \mathrm{~cm}^{2}$ ). Accumulation of ciliates is an exponential function of time as shown by the semi-log presentation in Fig. 6, and time to reach equilibrium distribution is proportional to the available area of the chamber (Fig. 7). The attraction is obviously chemically induced because ciliates readily accumulate around small capillary tubes filled with either peptone solution or bacteria suspension only allowing diffusion of soluble substances.

When ciliates swim in gradients of peptone or bacterial exudates 2 distinct swimming patterns can be distinguished. Starving ciliates (Fig. 1, right) or ciliates in areas with low bacterial concentrations (Fig. 8, left) swim in helices with occasional tumbles so that transportation rate depends on the steepness of the helix. In contrast, well fed or feeding ciliates (Figs. 1, left and 8, right) swim in closed circles and more or less stay in one spot. When swimming in circles a ciliary reversal occurs about once in every revolution so the cells swim in a new orbit with a slightly different plane. This kinetic response to the presence of bacteria will cause ciliates to accumulate in a food. When Strombidium sulcatum moves into increasing concentrations of bacteria, tangential velocity (swimming speed through the water) drops by about $40 \%$, but due to the change in swimming pattern from a helix to a nearly closed circle transportation rate is reduced by more than $95 \%$ (Fig. 9). Fig. 10 shows the modest range of tangential velocities found and the corresponding great span of transportation rates.

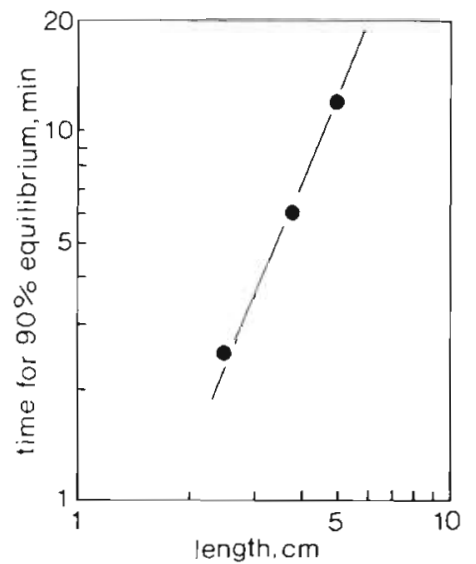

Fig. 7. Strombidium sulcatum. Time to reach $90 \%$ of the equilibrium abundance in a patch of bateria as function of chamber length

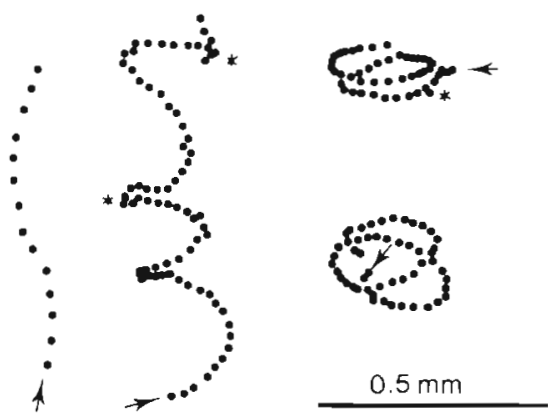

Fig. 8. Strombidium sulcatum. Paths plotted from video recordings of swimming ciliates. Time interval: $40 \mathrm{~ms}$. The 2 paths to the left are characteristic of starving cells, the 2 paths to the right for feeding cells. Tumbles are indicated by stars

The swimming pattern of Strombidium sulcatum and many other ciliates is characterized by a helical path. The helical movement can be thought of as a result of 2 superimposed rotations. Due to a propulsion 


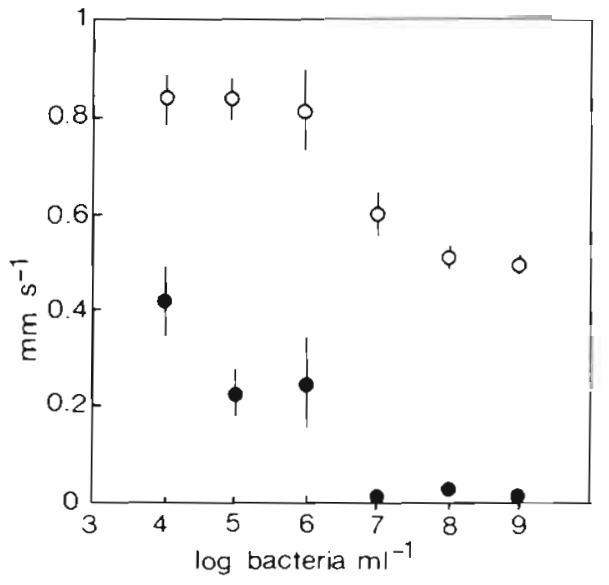

Fig. 9. Strombidium sulcatum. Tangential velocity $(0)$ and transportation rate $(\bullet)$ as function of bacterial concentration

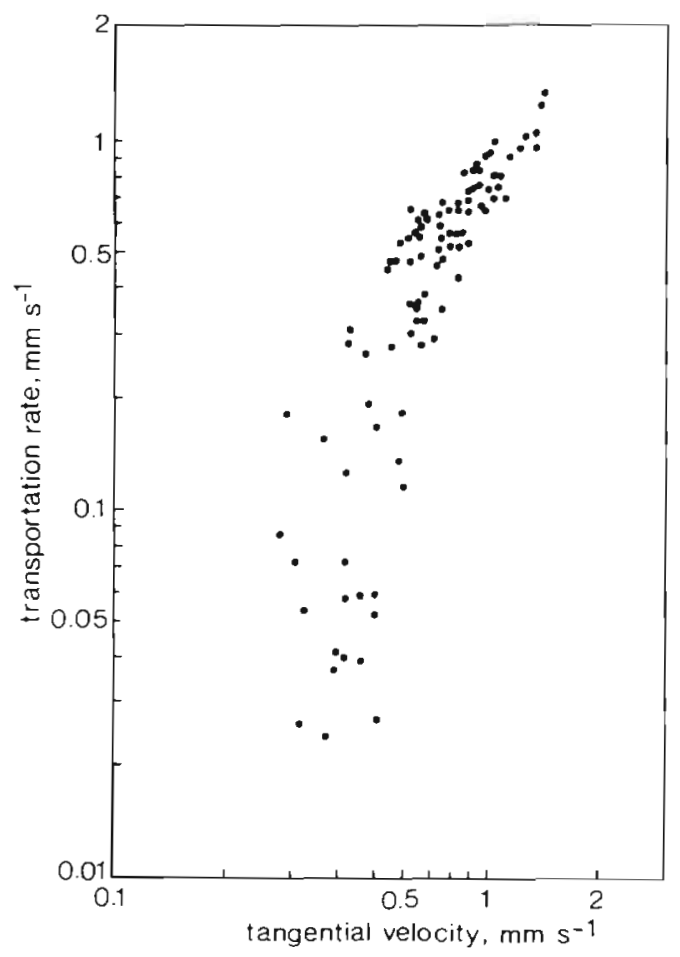

Fig. 10. Strombidium sulcatum. Transportation rate as function of tangential velocity

asymmetry, S. sulcatum tends to turn and this leads to a circular path with a characteristic angular velocity, $\omega_{0}$ (Fig. 11). An asymmetry in the ciliary propulsion may be inferred from the morphology of S. sulcatum (Fig. 1) where membranelles close to the oral cavity are small or absent. This is supported by the fact that, whether swimming in a circular or a helical path, the oral side always faces the axis of the movement. The other rotational component is a rotation around the long axis of the cell with an angular velocity, $\omega_{1}$; it is always

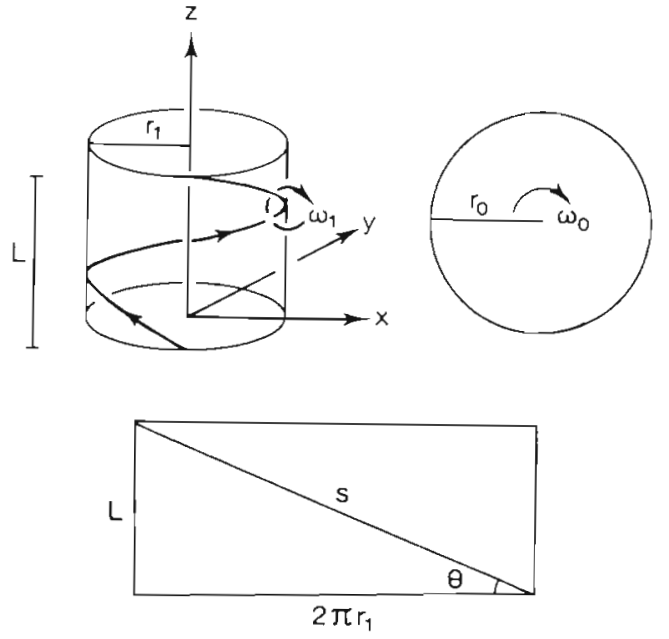

Fig. 11. Schematic representation of a helical motion caused by 2 superimposed rotations. Due to propulsive asymmetry a body moves in a circle with rotation rate $\omega_{0}$ and radius $r_{0}$. When a rotation around the long axis, $\omega_{1}$, is added a helical path results where $r_{1}$ is the radius of the helix, $L$ and $s$ are distance along the $z$-axis and the length of the helix during 1 period $\left[T=2 \pi /\left(\omega_{1}+\omega_{0}\right)\right]$ respectively, and $\theta$ is the pitch angle of the helix

clockwise when viewing the anterior pole and close observations reveal that axial rotation ranges between 0.5 and $3.5 \mathrm{~s}^{-1}$ in ciliates swimming in helices and is zero for ciliates swimming in circles. As discussed below this axial rotation must be caused by the membranelles generating water currents with a tangential component thus inducing a torque. When these 2 rotations are combined the swimming path will possibly be helical and the steepness of the helix will increase with the ratio $\omega_{1} / \omega_{0}$. The characteristics of the helix and its dependence on the 2 rotational components can be summarized in a mathematical description of transportation rate $V_{1}$ as a function of tangential velocity $\omega_{0} r_{0}$ and the ratio $\omega_{1} / \omega_{0}$ :

$$
v=\omega_{0} r_{0} /\left[1+\left(\omega_{0} / \omega_{1}\right)^{2}\right]^{1 / 2}
$$

A similar expression was used by Blake \& Sleigh (1974). That this is so can be seen from the following considerations. The tangential velocity is always $r_{0} \omega_{0}$ $=s / T$ (Fig. 11). The period, $T=2 \pi /\left(\omega_{1}+\omega_{0}\right)$ since the same side of the cell is always directed toward the axis, $z_{i}$ so $s=2 \pi I_{0} \omega_{0} /\left(\omega_{1}+\omega_{0}\right)$. From Fig. 11 it is seen that $L / 2 \pi r_{1}=\omega_{1} / \omega_{0}$ and that $s^{2}=(2 \pi)^{2} r_{1}^{2}+L^{2}$. Finally the transportation rate, $V=L / T$. Solving these equations for $v$ leads to Eq. (1)

A graphical representation (Fig. 12) shows that when $\omega_{1}$ goes from 0 to infinity transportation rate increases from 0 and approaches tangential velocity asymptotically. When $\omega_{1}$ is 0 this corresponds to swimming in a closed circle and transportation rate is accordingly 0 


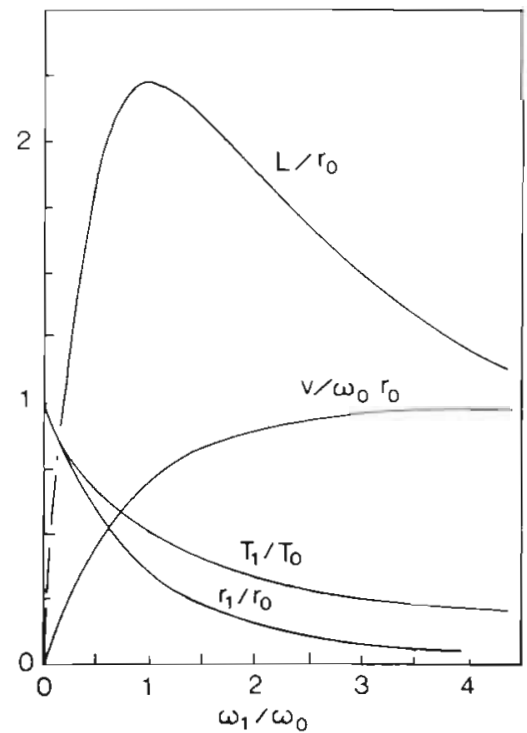

Fig. 12. Dimensionless presentation of transportation rate $(v)$, period $(T)$, transportation rate per $T(L)$ and radius of helix $\left(r_{1}\right)$ as a function of $\omega_{1} / \omega_{0}$

and when $\omega_{1}$ goes to infinity the swimming path approaches a straight line. Thus, by modulating the ratio $\omega_{0} / \omega_{1}$ a ciliate may in principle reduce the transportation rate from near tangential velocity to 0 without changing tangential velocity. In Strombidium sulcatum this is apparently achieved by changing the rate of rotation around the long axis $\omega_{1}$. Eq. (1) does not describe the swimming paths perfectly since there is some reduction in tangential velocity accompanying a reduction in transportation rate (Figs. 9 and 10). However, when swimming pattern is analyzed from video recordings there is a reasonable agreement with the predictions of Eq. (1) (Fig. 13). It must be stressed that

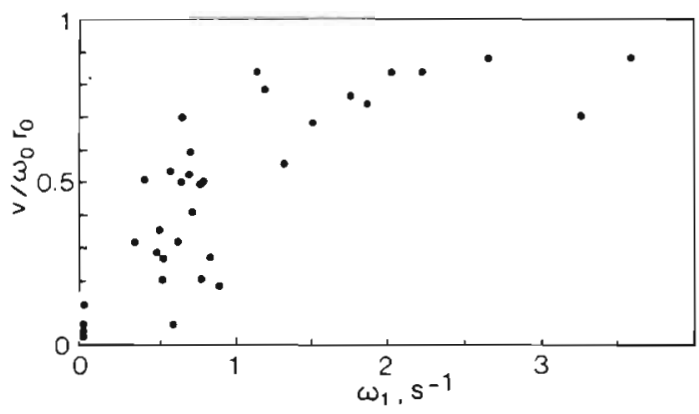

Fig. 13. Strombidium sulcatum. Transportation rate as function of axial rotation rate (legends as in Fig. 11)

the above is a formal description of what we believe goes on rather than a physical explanation. To achieve this it must be shown that the only net force acting on the cell is directed towards the axis of the helix. We are not able to offer an explanation of the motility pattern in hydrodynamical terms.

The dramatic reduction in transportation rate in Strombidium sulcatum leading to the accumulation of ciliates in bacterial patches is mainly caused by a reduction in transportation rate. Somehow ciliates have the ability to modulate axial rotation suggesting a change in the action of the membranelles. In most previously studied ciliates membranelles move water parallel to their plane and perpendicular to the beat of the individual cilia (Machemer 1974, Fenchel 1986). Observations on a hypotrich ciliate, Euplotes moebiusi, revealed that adjacent membranelles within each membranelle beat about $1 / 2$ cycle out of phase (Fenchel 1986). A metachronal wave moves along the cilia within each membranelle which draws water from the peristome and outwards, so that each pair of membranelles acts like a peristaltic pump. The membranelles show a symmetric beat cycle where the indistinguishable effective and recovery stroke both contribute to water flow explaining the observed continuous flow. In the heterotrich Stentor, however, Sleigh \& Aiello (1972) found that the membranelles move water at an acute angle to the effective stroke of individual cilia. The detailed function of membranelles in oligotrich ciliates has not previously been described and in an attempt to learn more about their action we video recorded swimming ciliates in strobe-light obtaining a series of still pictures with very short exposure times (Figs. $14 \mathrm{a}$ to $\mathrm{c}$ ). From these pictures the possible function may be inferred.

The membranelles show a symmetric beat cycle (frequency ca $35 \mathrm{~Hz}$ ) with no observed difference between effective and recovery strokes (Fig. 14b). Within a membranelle, cilia beat metachronically resulting in a wave that travels from the anterior to the posterior edge, evident as changes of the membranelle plane. There is also a metachronic wave pattern among membranelles with about 7 membranelles in each cycle. The function of the membranelles thus seems very similar to that found in Euplotes moebiusi (Fenchel 1986) suggesting a similar mechanism for water transport where the ciliary waves within a membranelle move water in the direction of the metachronic wave. The findings that water transport must be parallel to the membranelles imply that membranelles should be directed radially to prevent a torque which would cause the cell to rotate around its long axis (Fig. 15). On the other hand, to induce rotation membranelles should change into a turbine configuration generating water currents with a tangential velocity component. Examination of video recordings in strobe-light of Strombidium sulcatum swimming in circles and helices reveal differences in membranelle position. When swimming in circles the membranelles remain in the 


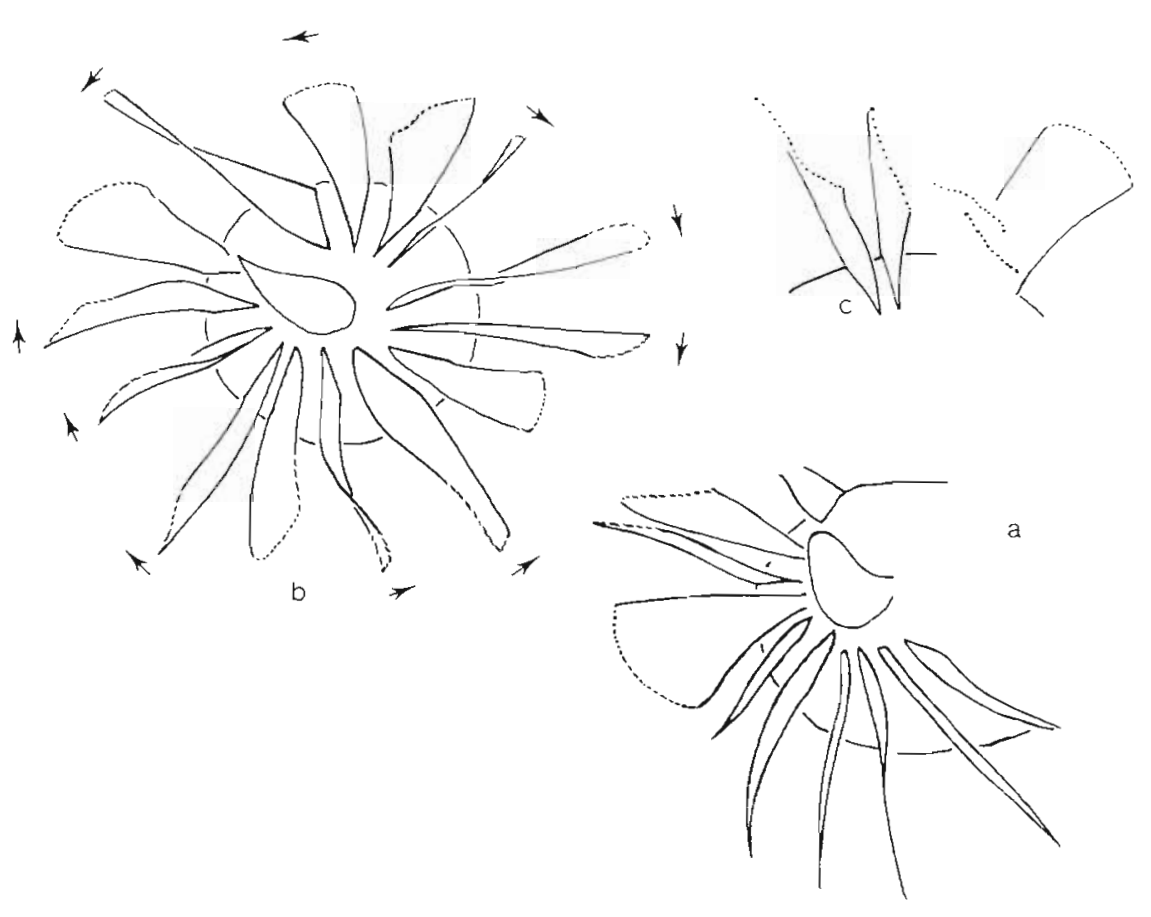

Fig. 14. Strombidium sulcatum. Video-recorded still pictures of ciliates exposed in strobe-light. (a) Ciliate swimming in circles; (b) ciliate swimming in a helix; (c) ciliate swimming in a helix viewed from the side. Arrows show the ciliary beat direction at the anterior rim of the membranelles
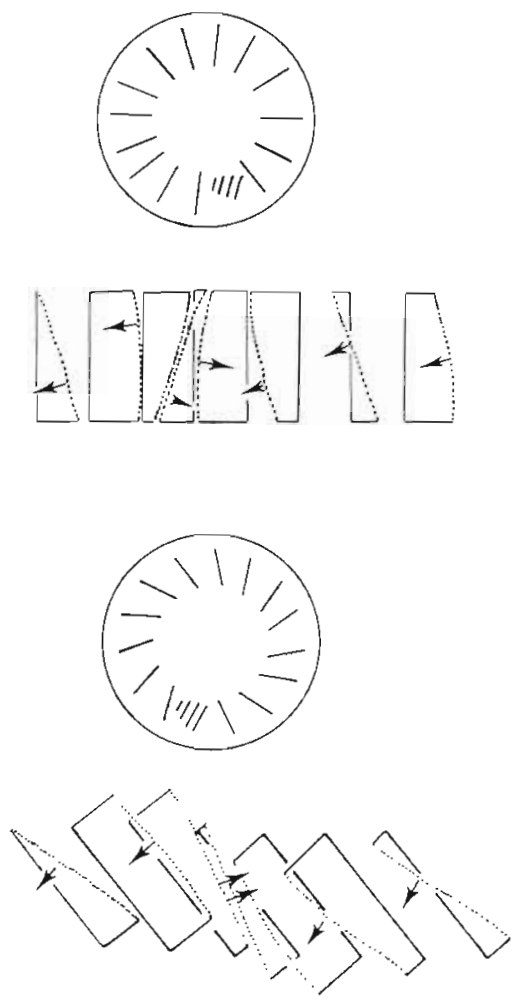

Fig. 15. Simulation of membranelle beating patterns as seen from the side assuming (above) radially oriented membranelles and (below) membranelles oriented with a tangential component. Arrows show the direction of the thrust acting on the water same plane during the beat cycle and the membranelle bases seem close to the anterior pole making the membranelles appear like spokes in a wheel (Fig. 14a). When swimming in helices the membranelle bases are more distant from the peristome with a tendency to a more tangential position (Fig. 14b). In addition, at each moment the distal parts of several membranelles are out of focus and have an apparent shorter length when viewed from above (Fig. 14b), indicating that beating of the membranelles has an up-down component. This is also apparent when membranelles are viewed from the side (Fig. 14c) These observations of membranelle position and beating planes are consistent with a change from radially orientated membranelles in circling ciliates. The beating pattern of membranelles assuming this change in orientation and based on the observed metachronic patterns is shown diagramatically in Fig. 15 and explains beating patterns observed. It shows how membranelles will have a more up-down beating component when they are tangentially oriented compared to the radially set membranelles. This is a consequence of the insertion of the membranelles on the curved cell surface so that a tangential displacement will add an up-down component to the bending plane of the membranelles.

How Strombidium sulcatum achieves this change of membranelle orientation is unknown. A hypothesis is that the shape of the cell is slightly changed through the action of contractile elements as known from other ciliates. A sphincter-like contraction of the peristome 
area might impose a strain on the membranelle bases causing them to change orientation. Indications that contractions of the peristome area in $S$. sulcatum are possible come from observations on ciliary reversals either in fixed (Fig. 1a) or in living ciliates (Fig. 16),

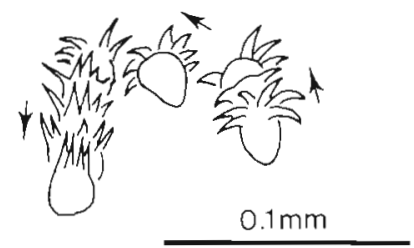

Fig. 16. Strombidium sulcatum. Tumbling behaviour by ciliary reversal (based on video recording). Time interval between drawings is $40 \mathrm{~ms}$

where the peristome is dramatically contracted and the membranelles directed anteriorly.

A different type of behavioural pattern related to the change in transportation rate was found when the vertical distribution of Strombidium sulcatum was studied. Well-fed ciliates always accumulate at the bottom but as the food resource becomes depleted ciliates begin to move up in the water column (Fig. 17).
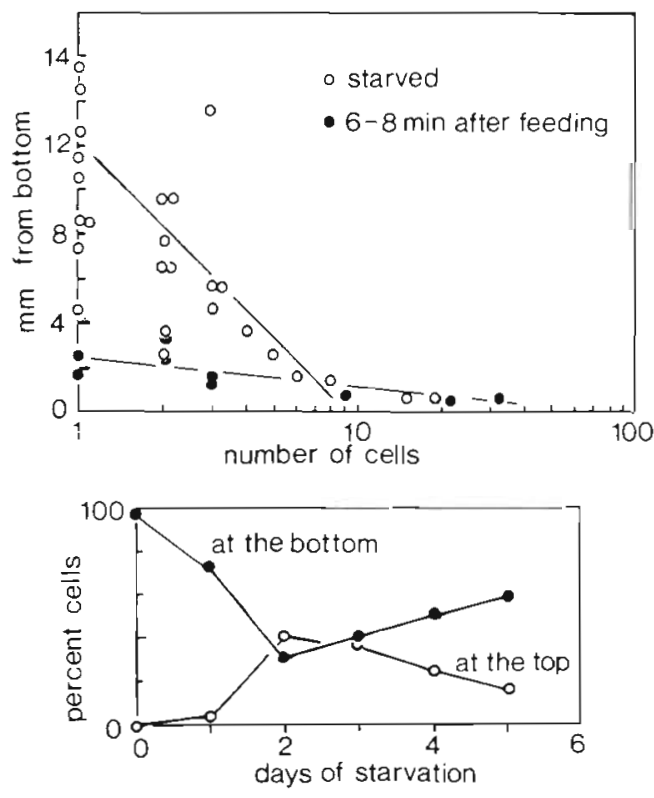

Fig. 17. Strombidium sulcatum. Above: vertical distribution in a spectrophotometer cell for starved and well-fed ciliates. Below: vertical distribution (measured as \% cells at top and bottom) in a $150 \mathrm{~mm}$ deep water-column as function of starvation

This may in part be explained as a balance between random motility and sinking velocity of the ciliates as described by Roberts (1970). When well-fed ciliates swim in circles the transportation rate is less than $50 \mathrm{um}$ $\mathrm{s}^{-1}$, so giving a low value of diffusivity; with a sinking velocity $\left(22 \pm 2 \mathrm{um} \mathrm{s}^{-1}\right)$ they are effectively drawn downwards. Upon starvation ciliates begin to swim in helices with transportation rates exceeding $400 \mathrm{um} \mathrm{s}^{-1}$ and so the cells tend to diffuse up in the water column. On the basis of transportation and sinking rates the theoretical model suggested by Roberts (1970) can explain some of the observed distributions. In some experiments with $150 \mathrm{~mm}$ deep water columns (Fig. 17) distributions were much more skewed towards the surface and this cannot result from random diffusion and gravitational sinking alone. Similar accumulations towards the surface in the absence of other stimuli are known from other ciliate species in spite of the absence of apparent gravity sensors. This upward drift has been interpreted as being caused by the interaction between sinking velocity, motility and cell asymmetry (Roberts 1970). A front-rear asymmetry of e.g. shape will cause the centre of drag and the centre of gravity to be separated resulting in a torque which tends to align the front-rear axis vertically. Some observations of $S$. sulcatum indicate that a hydrodynamical asymmetry is present. If fixed cells of $S$. sulcatum are allowed to sink freely they rapidly $\left(20 \pm 2^{\circ} \mathrm{s}^{-1}\right)$ reorientate until the membranelle zone points upwards. In addition, by treating starved $S$. sulcatum with $\mathrm{NiNO}_{3}$ or with artificial, calcium-free seawater they swim in steep helices almost without tumbles. This results in a pronounced accumulation at the surface and video recordings reveal that many ciliates show swimming paths curving upwards. From the analysed swimming paths reorientation rates can be calculated which are about half the rates $\left(13 \pm 2^{\circ} \mathrm{s}^{-1}\right)$ found for fixed ciliates. The cause of this reorientation is obscure, but it may be an asymmetry in shape where at least in starved ciliates the membranelle zone may shift the centre of drag to the anterior and thus induce reorientation with the membranelles upwards.

The question of vertical distribution of Strombidium sulcatum is further complicated by the amazing behaviour shown by well-fed ciliates when resuspended from the bottom. Immediately, ciliates dart towards the bottom at velocities exceeding $1500 \mathrm{um} \mathrm{s}^{-1}$ and in $30 \mathrm{~s}$ most ciliates are back to the bottom. If ciliates had to rely on sinking velocity this would not be possible. This behaviour is difficult to explain, but one clue may be the observation that it was only found in well-fed individuals with large cell size. An increase in cell volume in $S$. sulcatum is accompanied by a change of the cell shape since growth is localized to the anterior part of the cell with almost no change of the posterior end and the membranelle zone (Fig. 1). One suggestion is that the large anterior end will tend to sink faster than the small posterior end following 
Stoke's law and that this will cause reorientation with the anterior end downwards. This effect may dominate over an opposite reorientation tendency in smaller cells. Experiments with ciliates swimming in seawater with increasing density show that the tendency to swim downwards is reduced and eventually ceases in a highdensity medium (Table 1). The experiments show that

Table 1. Strombidium sulcatum. Average absolute swimming angle ( $\pm \mathrm{SD}$ ) to the vertical as function of medium density. Medium with the lowest density was made from seawater and the higher densities from mixtures of seawater and deuteriumoxide

\begin{tabular}{|cc}
\hline Density $\left(\mathrm{g} \mathrm{cm}^{-3}\right)$ & Swimming angle $\left(^{\circ}\right)$ \\
\hline 1.019 & $7.0 \pm 6.6(10)^{\circ}$ \\
1.047 & $29 \pm 22(25)$ \\
1.063 & $45 \pm 29(25)$ \\
- Sample size & \\
\hline
\end{tabular}

average absolute swimming angle to the vertical increases from $7 \pm 7^{\circ}$ in seawater, indicating a high directionality, to about $45 \pm 29^{\circ}$ in high density medium, which is expected for random motility. This reduction of directed movement is expected if the ability to swim downwards is caused by reorientation induced by a separation of the centre of gravity and centre of drag since raising the density reduces the effect of gravity and thence the reorientation torque. Although some questions remain concerning the vertical distribution of $S$. sulcatum it can be concluded that when ciliates are growing and have a large cell size they concentrate close to the bottom. The equilibrium distribution can be explained by the low motility and gravitational sinking, but the rapid return to the equilibrium when ciliates are resuspended requires a directed movement downwards. It is suggested that downward swimming is caused by hydrodynamical reorientation. When ciliates have exhausted their food resource they start to swim in helices and the motility increases. This accounts in part for the upward movement, but in addition starving ciliates, which have a different shape, tend to reorientate with the anterior end upwards giving the ciliates a directed movement towards the surface. Thus it seems to be a delicate balance of swimming pattern, sinking velocity and nutritional status that determines the vertical distribution of $S$. sulcatum. It may well be that most of these features are nonadaptive, but the general increase of diffusion of cells upon starvation which affects both horizontal and vertical distribution suggests an adaptive dispersal of cells to new patches

\section{Exploitation of patches}

The behaviour of Strombidium sulcatum reflects an adaptation to life in an environment where food is patchily distributed. The basic behavioural response to prey density is one of chemokinesis, that is, a modulation of motility as a function of the concentration of some chemical cue (Fig. 18). When a population of $S$.

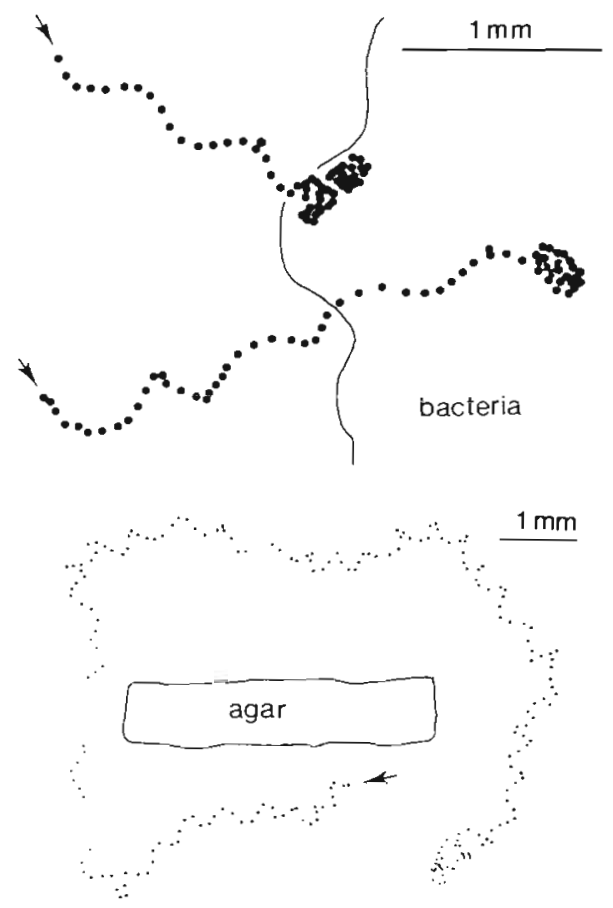

Fig. 18. Strombidium sulcatum. Above: swimming paths plotted from video recordings of 2 individuals entering a patch of bacteria (time interval: $80 \mathrm{~ms}$ ). Below: swimming path of a cell in the vicinity of a peptone agar block (time interval $200 \mathrm{~ms}$ )

sulcatum is allowed to spread in an environment with patches of food the process can be viewed as a diffusion process in which diffusion coefficients differ in- and outside patches. After some time a dynamic equilibrium is reached where the concentrations in- and outside patches are constant. The equilibrium concentration of cells is everywhere inversely proportional to their local motility, thus

$$
C_{p}=C_{o} \quad D_{o} / D p
$$

Where $C_{p}=$ cell concentration in the patch; $C_{0}=$ cell concentration outside the patch; $D_{0}$ and $D_{p}=$ local motilities (Okubo 1980). A time-dependent solution is likely to depend on details of the system such as the geometry of the patch. However, from dimensional considerations it is reasonable to assume that the time taken to reach equilibrium is proportional to the square of a length measure of the (closed) system and that 
deviations from the equilibrium decay exponentially with time at a rate which is proportional to the motility. To test if the behaviour of $S$. sulcatum accumulating in a bacterial patch (Fig. 6a) conforms to a distribution process as described above, estimates of the diffusion coefficients of the 2 modes of swimming are required. Estimates could be obtained in 2 ways. From analysis of swimming tracks transportation rate $(v)$ and time between tumbles $(\tau)$ can be directly measured and the diffusion coefficient (D) in a 2 dimensional environment approximated as:

$$
\mathrm{D}=v^{2} \cdot \tau / 4 . \text { (Okubo 1980) }
$$

Using this expression we found motilities of 0.0012 and $0.21 \mathrm{~mm}^{2} \mathrm{~s}^{-1}$ for feeding and starving cells, respectively or a ratio $D_{s} / D_{f}$ of about 175 (where $D_{s}$ and $D_{f}$ designate motilities of starved and feeding cells, respectively). Another method is to use the differences in vertical distribution between well-fed circling ciliates and starving ciliates swimming in helices. Assuming no hydrodynamical reorientation of cells the number of ciliates $(X)$ will be an exponential function (Fenchel \& Finlay 1984) of height from bottom $(h)$, sinking velocity $(u)$, and diffusion coefficient (D) given by:

$$
X(h)=e^{-h u / D}
$$

Accordingly the slopes of the semi-logarithmic vertical distributions will equal $u / D$ which experimentally (Fig. 17) were found to be about -0.025 and -1.45 for well-fed and starving ciliates respectively. With a measured sinking velocity of $22 \pm 2 \mu \mathrm{m} \mathrm{s}^{-1}$ the resulting diffusion coefficients are 0.88 and $0.015 \mathrm{~mm}^{2} \mathrm{~s}^{-1}$ giving a ratio of about 60 .

The experiments on cell accumulation such as the one shown in Fig. 6 gave somewhat variable results, but in general the concentration of ciliates in the bacterial patch was some 60 -fold higher inside the patch. While the above estimates of cell motility are inaccurate for a number of reasons the results suggest that the accumulation can be explained as a kinetic response. However, careful studies of Strombidium sulcatum swimming in an environment with a block of peptone agar revealed another behavioural response in addition to the described chemokinesis (Fig. 18). This behaviour is known as a transient response (see Fenchel 1987 and Fenchel \& Finlay 1986b for a discussion on terminology) and consists of tumbles or suppression of tumbles in response to the rate of change of some environmental cue perceived by the ciliate during one run (the length moved between tumbles). The response is called transient since it is triggered only where the gradient is sufficiently steep while on either side of the gradient the response is absent. In this way it differs from a kinetic response which results from different motilities in different, homogeneous environmental conditions. A

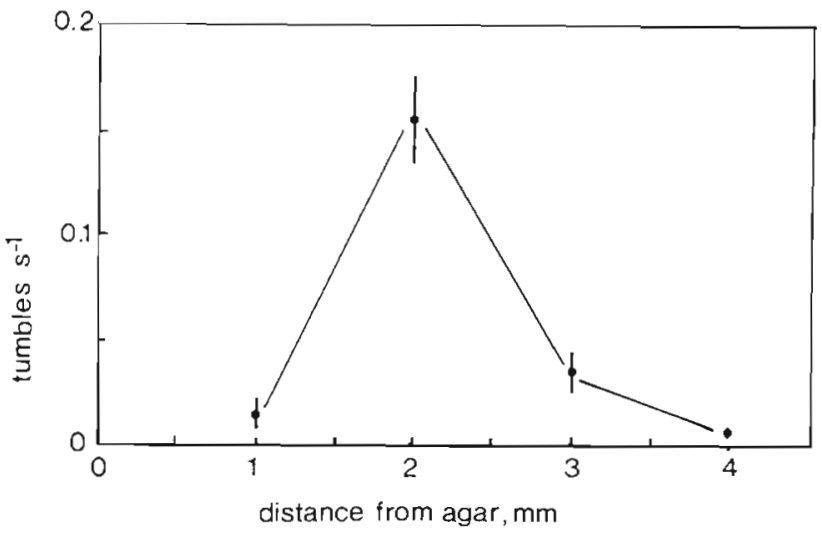

Fig. 19. Strombidium sulcatum. Tumbling frequency as function of distance from a peptone agar block.

famous example of a transient response is the avoidance reaction which prevents ciliates from entering unfavourable areas (Jennings 1906). When a ciliate swims up a gradient of some harmful substance it tumbles when some characteristic rate of change is exceeded and if the ciliate after tumbling swims down the gradient tumbling is suppressed and it will escape from the area. Note that a kinetic response in a similar situation could be fatal where a kinetic induction of tumbling to a raised concentration might lead to a trapping of the ciliate in a harmful patch.

The transient response shown by Strombidium sulcatum when swimming in a peptone gradient is similar to the avoidance reaction, but here tumbling is triggered when ciliates swim down a sufficiently steep gradient of an attractant (Fig. 18). Studies of many individuals showed that the induction of tumbling occurs at about $2 \mathrm{~mm}$ from the agar block presumably indicating the level of concentration for which the ciliates are most sensitive to changes (Fig. 19). Whenever a ciliate approaches the outskirts of a food patch it will tumble and thereby remain in the vicinity of the food patch centre and when the ciliate eventually encounters the patch centre a kinetic response is induced which reduces motility. In a way the transient response makes a patch appear larger and the encounter rate of new patches will be enhanced. It is more likely to play a role in keeping the cells in close vicinity to a prey patch as a 'fine tuning' of the kinetic response since sufficiently steep chemical gradients are not likely to extend very far from the patch.

It may be concluded that the attraction of Strombidium sulcatum to food patches can largely be explained as a chemokinetic response. Through a reduction in axial rotation, motility is reduced when a certain concentration of food is encountered and upon food depletion motility is again increased and the ciliates spread to new patches. The shift in motility 
occurred at a threshold of $10^{6}$ to $10^{7}$ bacteria $\mathrm{ml}^{-1}$ (Fig. 9), a higher concentration than found in free seawater. This makes sense since no shift in motility would occur if the concentration threshold was similar to or lower than found between food patches. Note that a serious behavioural constraint is the inability to directly sense the direction of a chemical gradient, which $S$ sulcatum shares with most protozoa.

An interesting question is on what length scale the behaviour of Strombidium sulcatum is appropriate. How far can ciliates travel in search for new food patches? The time to find a bacterial patch was found to increase with the square of the length of the chamber (Fig. 7). If ciliates which leave an exploited patch are assumed to diffuse with a diffusion coefficient $D_{0}$ the time, $t$, to move a certain distance, $l$, can be approximated as:

$$
t \propto 1^{2} / D_{0}
$$

In the growth experiments it was found that $S$. sulcatum could survive starvation for maximally about $100 \mathrm{~h}$ (Fig. 2). Extrapolation of the data shown in Fig. 7 shows that a ciliate could on average move ca $0.5 \mathrm{~m}$ before succumbing to starvation. This indicates the scale of patchiness which $S$. sulcatum is adapted to exploit.

A kinetic response implies that motility is reduced when conditions are favourable; however, the membranelles serve as a filtering apparatus for food particles as well as for locomotion. The only 2 ways to reduce the motility to zero when a food patch has been encountered is therefore either to attach to some immobile surface or to continously move in a circle. Strombidium sulcatum does not have the ability to attach and the transformation from helical swimming to a closed circle is the best solution. In reality the ciliates do not swim in a constant circle but due to tumbling about once every revolution the circular path is slightly rotated and translated resulting in the observed slow diffusion rates around $0.01 \mathrm{~mm}^{2} \mathrm{~s}^{-1}$ (Fig. 8). These small recurrent perturbations of the circular path are probably an adaption to avoid refiltering water already cleared for prey. It is interesting to note that some benthic Strombidium species seem to have adopted the attachment strategy (KahI 1932, Fauré-Fremiet 1950, 1969). These species are reported to possess either Iong thigmotactic membranelles or mucous threads which allow for temporary attachment to surfaces and although not studied it is likely that attachment and detachment are controlled by prey density.

Most known Strombidium species are planktonic but very similar in morphology to $S$. sulcatum and other benthic species (Kahl 1932). Why are some species found in the pelagic and others in benthic habitats? Their particle selection is similar and it is possible to grow $S$. sulcatum on microalgae and at least the planktonic $S$. vestitum can grow on bacteria and heterotrophic flagellates (pers obs.) indicating that they could survive and reproduce in either habitat. One difference in planktonic Strombidium species is their seemingly weak ability to respond to food gradients (Jonsson unpubl.). This probably indicates that their prey is more or less homogeneously distributed in their pelagic habitats, at least on the scale of ciliates. However, selection of habitat may have a proximal cause not coupled to prey availability. Since the pelagic and benthic habibtats are separated vertically, habitat selection could be achieved by behaviour that causes different species to swim either upwards or downwards. This is supported by the studies of the vertical distribution of $S$. sulcatum discussed above together with observations showing that many planktonic species have a net upward swimming movement probably caused by hydrodynamical reorientation of asymmetric cells (Jonsson unpubl.).

The behaviour of Strombidium sulcatum shows how a few simple mechanisms suffice for exploiting a heterogeneously distributed food resource. Many protozoa swim in a helix similar to $S$. sulcatum and the ability to modulate transportation rate by changing axial rotation may be widespread among species living on patchily distributed food, or wherever a kinetic response to environmental change is desirable without cutting swimming speed.

Acknowledgements. We are indebted to Jeanne Johansen and Ilse Duun for assistance with experimental work. We also thank Dr Fereidoun Rassoulzadegan who provided the culture of Strombidium sulcatum isolated from the Mediterranean Sea. The study was supported by the Danish Natural Science Research Council (Grants Nos. 11-6089, 11-6480, 11-4688), the Carlsberg Foundation, the Swedish Natural Science Research Council through contract B-DT 1860-107 and by a Grant from the Nordic Council for Marine Biology.

\section{LITERATURE CITED}

Andersen, P., Sorensen, H. M. (1986). Population dynamics and trophic coupling in pelagic microorganisms in eutrophic coastal waters, Mar Ecol. Prog. Ser. 33: 99-109

Blake, J. R., Sleigh. M. A. (1974). Mechanics of ciliary locomotion. Biol. Rev. 49: 85-125

Borror, A C. (1965). New and little-known tidal marsh ciliates. Trans. Am. Micros. Soc. 84: 550-565

Fauré-Fremiet, E. (1924). Contribution à la connaissance des infusoires planktoniques. Bull. Biol. Fr Belg. 6 (Suppl.): $1-171$

Fauré-Fremiet, E. (1950). Ecologie des Cilıés psammophiles littoraux. Bull. Biol. Fr. Belg. 84: 35-75

Fauré-Fremiet، E. (1969). Remarques sur la systématique des Ciliés Oligotrichida. Protistologica 5: 345-352

Fauré-Fremiet, E., Ganier, M. M.-Cl. (1970). Structure fine du Strombidium sulcatum $\mathrm{Cl}$ et $\mathrm{L}$. (Ciliata Oligotrichida). Protistologica 6: 207-223 
Fenchel, T. (1982). Ecology of heterotrophic microflagellates. II. Bioenergetics and growth. Mar Ecol. Prog. Ser. 8: 225-231

Fenchel, T. (1986). Protozoan filter feeding. Prog. Protistol. 1. 65-113

Fenchel, T (1987). Ecology of Protozoa. Science Tech/ Springer Verlag, Madison

Fenchel, T., Finlay, B. J. (1983). Respiration rates in heterotrophic, free-living Protozoa. Microb. Ecol. 9: 99-122

Fenchel, T., Finlay, B. J. (1984). Geotaxis in the ciliated protozoon Loxodes. J. exp. Biol. 110: 17-33

Fenchel, T., Finlay, B. J. (1986a). The structure and function of Müller vesicles in loxodid ciliates. J. Protozool. 33: 69-76

Fenchel, T., Finlay, B. J. (1986b). Photobehavior of the ciliated protozoon Loxodes: taxic, transient, and kinetic responses in the presence and absence of oxygen. J. Protozool. 33: $139-145$

Finlay, B. J., Fenchel, T. (1986). Photosensitivity in the ciliated protozoan Loxodes: pigment granules, absorption and action spectra, blue light perception, and ecological significance. J. Protozool. 33: 534-542

Finlay, B. J., Berninger, U.-G., Stewart, J. L., Hindle, R. M., Davison, W. (1987). Some factors controlling the distribution of two pond-dwelling ciliates with algal symbionts (Frontonia vernalis and Euplotes daidaleos). J. Protozool. 34: $349-356$

Heinbokel, J. F. (1978). Studies on the functional role of tintinnids in the Southern California Bight. I. Grazing and growth rates in laboratory cultures. Mar Biol. 47: $1977-189$

Inoué, S. (1986). Video microscopy. Plenum Press, New York

Jennings, H. S. (1906). Behavior of the lower organisms. Columbia Univ. Press, New York

Jonsson, P. R. (1986). Particle size selection, feeding rates and growth dynamics of marine planktonic oligotrichous ciliates ( Ciliophora: Oligotrichina). Mar. Ecol. Prog. Ser. 33: $265-277$

Jonsson, P. R. (1987). Photosynthetic assimilation of inorganic carbon in marine oligotrich ciliates (Ciliophora, Oligotrichina). Mar. Microb. Food Webs 2: 55-68

Kahl, A. (1932). Urtiere oder Protozoa. 1. Wimperntiere oder Ciliata (Infusoria). 3. Spirotricha. In: Dahl, F. (ed.) Die Tierwelt Deutschlands und der angrenzenden Meeresteile. Gustav Fischer Verlag, Jena, p. 399-650

Laval-Peuto, M. Febvre, M. (1986). On plastid symbiosis in
Tontonia appendiculariformis (Ciliophora, Oligotrichina). BioSystems 19: 137-158

Leergaard, C. (1915). Untersuchungen über einige Planktonciliaten des Meeres. Nytt Mag. Naturv. 53: 1-37

Levandowsky, M., Hauser, D. C. R. (1978). Chemosensory responses of swimming algae and protozoa. Int. Rev. Cytol. $53,145-210$

Machemer, H. (1974). Ciliary activity and metachronism in Protozoa. In: Sleigh. M. A. (ed.) Cilia and flagella Academic Press, London, p. 199-286

McManus, G. B., Fuhrman, J. A. (1986). Bacterivory in seawater with the use of inert fluorescent particles. Limnol. Oceanogr. 31: 420-426

Naitoh, Y., Eckert, R. (1974). The control of ciliary activity in Protozoa. In: Sleigh, M. A. (ed.) Cilia and flagella. Academic Press, London, p. 305-352

Okubo, A. (1980). Diffusion and ecological problems: mathematical models. Springer-Verlag, Berlin

Reisser, W., Häder, D.-P. (1984). Role of endosymbiotic algae in photokinesis and photophobic responses of ciliates. Photochem. Photobiol. 39: 673-678

Rivier, A., Brownlee, D. C., Sheldon, R. W., Rassoulzadegan, F. (1985). Growth of microzooplankton: a comparative study of bacterivorous zooflagellates and ciliates. Mar. Microb. Food Webs 1: 51-60

Roberts, A. M. (1970). Geotaxis in motile micro-organisms. J. exp. Biol. 53: 687-699

Sleigh, M. A., Aiello, E. (1972). The movement of water by cilia. Acta Protozool. 9. 265-277

Song, P. S., Häder, D. -P., Poff, K. L. (1980). Phototactic orientation by the ciliate Stentor coeruleus. Photochem. Photobiol. 32: $781-786$

Stoecker, D. K., Michaels, A. E., Davis, L. H. (1987). Large proportion of marine planktonic ciliates found to contain functional chloroplasts. Nature, Lond. 326: 790-792

Van Houten, J., Hansma, H., Kung, C. (1975). Two quantitative assays for chemotaxis in Paramecium J. comp. Physiol 104: 211-223

Van Houten, J., Hauser, D. C. R., Levandowsky, M. (1981). In: Levandowsky, M., Hutner, S. H. (eds.) Biochemistry and physiology of protozoa, Vol 4. Academic Press, New York, p. $67-124$

Zobell, C. E. (1941). Studies on marine bacteria, I. The cultural requirements of heterotrophic aerobes. J. mar. Res. 4. $42-75$ 